УДК 791:811.163.41'367.62

https://doi.org/10.18485/primling.2017.18.4

Tijana Marković

Univerzitet u Beogradu, Filološki fakultet

\title{
PRIRODNOST JEZIKA U DOBROM FILMSKOM DIJALOGU: ANALIZA FONETSKI NEREALIZOVANOG SUBJEKTA I PRIPOVEDAČKOG ISTORIJSKOG PREZENTA U KORPUSU FILMSKIH DIJALOGA
}

Sažetak: Cilj ovog rada jeste da utvrdi u kojoj meri svojstva govornog jezika imaju uticaj na percipirani kvalitet filmskog dijaloga. Pojmovi „dobar” i „loš” dijalog, kao estetski sudovi, oduvek su bili podložni različitim tumačenjima kritike, ali jedna od karakteristika koja je oduvek pominjana u kontekstu kvalitetnog dijaloga jeste njegova sličnost sa svakodnevnim govorom, odnosno prirodnost. Dijalozi filmova Pre svitanja i Petparačke priče u filmskoj kritici važe za savremene filmove sa najboljim dijalogom, dok je film Soba predstavnik kategorije „lošeg” dijaloga. Stoga, rad će u korpusu ovih filmova analiziati dva svojstva govornog jezika - fonetski nerealizovan subjekat i pripovedački istorijski prezent, te pokušati da odredi njihovu lingvističkodramaturšku funkciju.

Ključne reči: filmski dijalog, govorni jezik, fonetski nerealizovan subjekat, pripovedački istorijski prezent

\section{Uvod}

Film kao pokretna slika, jeste jedna od najčešćih fraza na koju se nailazi u razmatranjima prirode ovog medija. Međutim, ako film čine pokretne slike, onda je ono što te slike pokreće dijalog. Pa ipak, poznata je činjenica da je filmski dijalog kroz istoriju tradicionalno bio u senci slike, zahvaljujući uvreženoj mantri „Ne opisuj već pokaži”. Ovakav stav prema filmu ogleda se u brojnim studijama teorije filma i priručnicima o filmskoj umetnosti, u kojima su nebrojene stranice posvećene narativnoj strukturi scenarija, fotografiji, montaži, dok na poslednje mesto dolazi dijalog, koji kao dovoljno transparentan i jednostavan ne provocira dalje debate o prirodi svoje strukture (Kozlof 2000: 6). Međutim, sa razvojem eksperimentalnih scenarija proizvedenih od strane veštačke inteligencije, postavlja se nekoliko interesantnih pitanja o značaju dijaloga kao jezičke, a ne samo narativne celine. Uzmimo u obzir sledeći odlomak iz filma Sunspring $(2016)^{1}$ :

1 Scenario preuzet sa sajta Docdroid URL: https://www.docdroid.net/lCZ2fPA/sunspring-final.pdf 
H2: You should see the boys and shut up.

H: I saw him again... The way you were sent to me...that was a big honest idea. I am not a bright light.

(...)

H: I want to see you too.

H2: What do you mean?

H: I'm sorry, but I'm sure you wouldn't even touch me.

H2: I don't know what you are talking about.

Iako, čitajući ovaj dijalog počinjemo da se obrćemo u cikličnim krugovima tražeći smisao govornog čina, usmeravanjem pažnje na sintaksičku strukturu rečenice slika postaje jasnija. Te tako, u eksperimentu izvedenom za potrebe ove studije, u kome je zadatak iskusnog scenariste bio da dâ svoj sud o kvalitetu dijaloga, odlomak je ocenjen visokom ocenom, uz sledeće komentare: razmena je brza i dinamična, a kratke i odsečne rečenice, sredstvo slikanja H2, kao hladne i nezainteresovane heroine, dok upotreba epistemičke modalnosti i deskriptivnih, nedovršenih rečenica ističe lik H kao osećajnog i maštovitog junaka. Stoga, jasno je da rečenična struktura u jednom semantički praznom dijalogu u stilu Luis Kerolovog Džebervokija, itekako doprinosi našem opažanju onoga što se odigrava na ekranu.

Međutim, ne može se reći da svaki dijalog ima moć da strukturom upotpuni scenario; mnogo je primera u svetu filma, čiji se dijalog karakteriše kao izveštačen i „neprirodan,” pa ipak, do odgovora na pitanje šta čini „prirodan” dijalog teže se dolazi. „Slušaj kako ljudi govore!”, „Realističan i autentičan dijalog je ključ dobrog scenarija!” jesu samo neki od čestih saveta upućenih mladim scenaristima, koji, iako se pozivaju na prirodnost kao osnovnu karakteristiku ovakvog dijaloga, malo govore o tome kako se takva osobina postiže. Ako pođemo od intuitivne pretpostavke da su kvalitet filmskog dijaloga i njegova sličnost sa svakodnevnim govornim jezikom usko povezani, rad će pokušati da odgovori na pitanje šta to čini dobar filmski dijalog, te da li on u potpunosti reflektuje sintaksu spontanog govora, ili je prirodnost privid koji nastaje umešnim modelovanjem pisanog teksta, sa ciljem da napisano zvuči kao da je izgovoreno.

Ispitivanje nivoa sličnosti filmskog dijaloga i govornog jezika izvršeno je analizom dva svojstva spontanog govora - fonetski nerealizovanog subjekta i pripovedačkog istorijskog prezenta, na korpusu dijaloga tri filma: Petparačke priče (1994), Pre svitanja (1995) i Soba (2003). Svojstva spontanog govora izabrana su na osnovu visokog nivoa zastupljenosti u svakodnevnom diskursu, ali i na osnovu pragmatske funkcije koju u određenim situacionim kontekstima vrše, a koja je u skladu sa narativnim zahtevima koje dobar scenario treba da ispuni, kao što su dinamičnost razmene, izbegavanje ponavljanja, živopisnost narativa.

\section{Faktori koji utiču na prirodnost filmskog dijaloga}

Kada govorimo o sličnosti filmskog dijaloga sa svakodnevnim govorom, čini se da je većina scenarista usaglašena oko ideje da dobar filmski dijalog, iako pojman od strane gledalaca kao prirodan, u većini slučajeva to nije. Scenarista i teoretičar Robert MekKi, autor takozvane „Biblije za scenariste” Substance, Structure, Style and the Principles of Screenwriting, navodi da dijalog nema svojstva spontane konverzacije, jer ukoliko bismo 
oslušnuli bilo koji razgovor koji se odvija oko nas, shvatili bismo da je njegova struktura puna redundansi, nepreciznog odabira vokabulara, lažnih početaka i nedovršenih rečenica, koje retko imaju početak i kraj (McKee 1999: 388). Pa ipak, ovakvo zapažanje odnosi se na disfluentnosti koje su sastavni deo jezičke performanse u realnom vremenu, dok o sličnosti sa sintaksičko-pragmatičkim aspektima govornog jezika malo toga saznajemo.

Prilikom pisanja filmskog scenarija, prisutno je nekoliko faktora koje autor(i) moraju uzeti u obzir, te koji utiču na nivo autentičnosti jezika. Naime, filmski dijalog prvobitno nastaje kao pisani tekst, u okviru određenih pravila formatiranja, prema kojima prosečna dužina celokupnog scenarija ne bi trebalo da prelazi 110 pisanih stranica za film u trajanju od 90 minuta, odnosno 20000 reči. $^{2}$ Stoga, jasno je da će filmski govor, u cilju ispunjavanja produkcijskih i komercijalnih zahteva, biti svedeniji i koncizniji u odnosu na spontanu konverzaciju, što se prvenstveno odražava na odsustvo spomenutih disfluentnosti.

Takođe, bitna je uloga publike kao pasivnog učesnika u razmeni, te je jedan od osnovnih zahteva pisanja scenarija upravo kreiranje dijaloga koji će sa jezičke strane u potpunosti biti razumljiv gledaocima. Nikol Baumgarten ovde napominje da se jezik na filmu neminovno razlikuje od svakodnevnog govora, jer svaka izgovorena reč mora biti razumljiva gledaocu, čak i kad bi u identičnoj realnoj situaciji, mogla biti izostavljena ili izmenjena (Baumgarten 2003: 21).

Na kraju, za izbor jezičkih sredstava presudna je kategorija žanra, ali i tendencija da se određene forme, registri i vernakularni oblici koriste u većoj meri nego što je to slučaj u realnim okolnostima, ne bi li se dijalog učinio interesantnijim i ekspresivnijim.

\section{Svojstva govornog jezika}

Prilikom analize govornog jezika, neophodno je osvrnuti se na Ličovu gramatiku govornog jezika (Leech, 1998), Biberovu Multidimenzionalnu analizu varijacije registara (Biber, 1988), u kojoj su identifikovane važne morfo-sintaksičke kategorije karakteristične za govorni jezik, potom na Kvaljovu studiju svojstava govornog jezika u TV sitkomu Prijatelji (Quaglio, 2009) kao i na studiju Pierfranke Forčini u kojoj se korpusnom analizom porede lingvističke karakteristike filmskog dijaloga sa spontanim govorom (Forchini, 2011). U pomenutim studijama, utvrđeno je da su elipsa, kao i fonetski nerealizovan subjekat, frekventna svojstva govornog jezika. U dramaturškom smislu, može se smatrati da fonetski nerealizovan subjekat ima funkciju postizanja dinamičnosti i spontanosti celokupne diskursne celine, te pisac Harvi Čepmen, savetuje sledeće:

„Don't write in complete, grammatical sentences, because very few people do, at least in informal conversations. Do you want to go to the park? sounds stiff. Want to go to the park? is better." (Chapman, 2017).

S druge strane, prema Bajberovoj analizi, glagoli u sadašnjem vremenu imaju veliku zastupljenost u spontanom, neformalnom govornom jeziku, što Bajber objašnjava tendencijom koverzacionog čina da bude vezan za odrednice sada i ovde (Biber 1999: 458).

2 Podaci preuzeti sa veb sajta Tameri guide for writers http://www.tameri.com/format/wordcounts.html 
U tom smislu, komunikativna funkcija istorijskog prezenta, u svakodnevnom govoru, a pre svega u filmskom dijalogu, jeste da učini naraciju interesantnijom i interaktivnijom, te da sagovorniku, odnosno gledaocu približi događaje iz prošlosti koji se opisuju.

\section{Selekcija filmova}

Korpus filmova za ovo istraživanje sastavljen je na osnovu nekoliko kriterijuma. Da bi se utvrdilo kakvu ulogu svojstva govornog jezika igraju u percepciji filmskog dijaloga, kao osnovni kriterijum postavljena je evaluacija dijaloga od strane filmske kritike i publike. Neosporno je da je svaka elvaluacija estetskih formi zasnovana na subjektivnom doživljaju, te je zbog toga kvantitativnom metodom pretraživanja filmskih revija, časopisa, internet foruma i stranica posvećenih savremenom filmu, utvrđena lista najfrekventnijih filmova u kontekstu diskusija o dobrom odnosno lošem filmskom dijalogu.

S obzirom na prirodu filmskog medija da reprezentuje stvarnost, jedan od kriterijuma za sastavljanje korpusa filmova, bio je i taj da radnja filmova bude zasnovana na svakodnevnim situacijama i interpersonalnim odnosima u savremenom kulturnom kontekstu, koji posledično reflektuju i savremenu upotrebu jezika. Stoga, u obzir su uzeti filmovi američkog jezičkog varijeteta nastali posle 1990. godine, kao i svi žanrovi osim naučno fantastičnih ${ }^{3}$ i žanrova istoijskikih drama.

Finalnom selekcijom, izabrani su filmovi Pre svitanja (1995) Ričarda Linklejtera, Petparačke priče (1994) Kventina Tarantina i Soba (2003) Tomija Vajsoa. Dijalozi filmova Pre svitanja (romantična drama) i Petparačke priče (gangsterski film/crna komedija/ akcija), ocenjeni su najvišim ocenama od strane filmske kritike, kao i publike; film Pre svitanja, izabran je odlukom gledalaca na sajtu Reddit za film sa najrealističnijim dijalogom u istoriji kinematografije, upravo zbog svog fokusa na svakodnevni spontani jezik, dok je dijalog filma Petparačke priče komentarisan od strane filmske kritike kao jedan od retkih koji je ušao u vernakularni govor pop kulture. S druge strane, film Soba (drama), od svog nastanka ima status gotovo kultnog filma, upravo zahvaljujući svom dijalogu, koji prema mnogim kritičarima važi za najgori dijalog svih vremena.

Dijalozi sva tri filma, transkribovani su za potrebe ovog istraživanja, s obzirom da u originalnim verzijama scenarija dostupnim na Intenetu, često nisu zabeležena sva svojstva govornog jezika nastala kao plod glumačke interpretacije datog teksta. Korpus se sastoji od 36667 reči.

\section{Analiza rezultata}

\section{Fonetski nerealizovan subjekat}

Jezike prema pro-drop parametru možemo podeliti na osnovu toga da li dopuštaju izostavljanje subjekta u finitnoj klauzi; Lilijan Hegeman navodi da pro drop jezici, kao što su

3 Iako u filmove naučno fantastičnog žanra spadaju i ostvarenja poput Matriksa koji sadrže narative i likove koji jednim delom jesu vezani za svakodnevne situacije, oni nisu uzimani u obzir. 
španski, srpski, italijanski dopuštaju izostavljanje subjekta zbog svojstva bogate inflekcione morfologije (Hegeman 2011, 91). S obzirom na to da je engleski jezik siromašan inflekcionim formama, mogućnost fonetski nerealizovanog subjekta (u daljem tekstu FNS) načelno nije dozvoljena, a engleski jezik se ne svrstava u PRO-drop jezike. Pa ipak, rezultati korpusa govornog jezika govore suprotno, ${ }^{4}$ te se FNS smatra legitimnim ukoliko postoji tematski antecedent na koji se odnosi, ili ako je tematski referent lako nadoknadiv na osnovu konteksta.

Sumirajući rezultate prethodnih istraživanja Lora Bejli (Bailey 2011: 25) navodi sledeći model distribucije FNS-a:

1) Fonetski nerealizovan subjekat se može pojaviti samo u glavnoj rečenici

2) Subjekat može biti izostavljen samo na početku rečenice

3) Fonetski nerealizovan subjekat može biti nosilac obeležja lica i broja

4) Potreban je blizak antecedent da bi se fonetski nerealizovan subjekat mogao odrediti

Primeri u nastavku rada, analizirani su na osnovu ovih predikcija.

Broj FNS-a u dijalozima tri filma predstavljen je u sledećoj tabeli.

\begin{tabular}{|l|l|}
\hline Film & Fonetski nerealizovan subjekat \\
\hline Before Sunrise & 3 \\
\hline Pulp Fiction & 23 \\
\hline The Room & 0 \\
\hline
\end{tabular}

U filmu Pre svitanja nije pronađen veliki broj FNS-a; dva primera su obeležena za prvo lice jednine, dok se u poslednjem slučaju radi o ekspletivnom subjektu. Ovi rezultati su u skladu sa rezultatima Lore Bejli, koja navodi da je najveći broj FNS-a obeleženo prvim licem jednine, dok ostatak čini FNS u drugom licu jednine, kao i ekspletivi. Takođe, zanimljiv je i primer ekspletivnog subjekta it u primeru (1) koji zauzima poziciju najvišeg reda, te stoga ne poseduje eksplicitan antecedent, niti je povezan sa pomerenim elementom koji je ostavio trag u rečenici. Pa ipak, gledalac jasno može da identifikuje referenta iz vizuelnog konteksta, u kome izgovorena rečenica predstavlja komentar performansa kome su glavni likovi svedočili. Takođe, u originalnom scenariju, ova Džesijeva replika ne postoji, te je ovo ujedno i primer improvizovanog teksta, koji sadrži svojstvo govornog jezika.

(1) Jesse: So, birth dance, huh?

$\varnothing$ Looked like a mating dance to me.

Iz malog broja FNS-a u scenariju filma Pre svitanja, možemo zaključiti da ovo svojstvo govornog jezika nije imalo presudnog značaja u stvaranju dijaloga koji zvuči prirodno, što može ukazivati na to da za romantične drame kao žanr, nije potrebna ekonomičnost jezika, kojom se prenosi veliki broj informacija sa malo reči.

4 Trasher (1974), Haegeman \& Ishane (2001) bave se fonetski nerealizovanim subjektom kako u pisanom tako i u govornom engleskom jeziku. 
U filmu Petparačke priče, broj FNS-a znatno je veći, a pretpostavke o distribuciji većinom su ispunjene, osim u slučaju eksplicitnog antecedenta, što Hegeman i Išan (Haegeman\&Ishane 1999:124) objašnjavaju kao posledicu činjenice da FNS zauzima inicijalnu poziciju u klauzi, te da upravo zbog prirode takve pozicije ostaje bez antecedenta

Pa ipak, istaknuti su slučajevi u sastavnim rečenicama u kojima FNS ne zauzima inicijalnu poziciju:

(2) Capt. Coons: Five long years, he wore this watch up his ass.

Then he died of dysentery [and] $\varnothing$ give me the watch.

(3) Young man: There's too many foreigners own liquor stores, $\varnothing$ don't even speak fuckin' English.

Lora Bejli u svom korpusu nalazi primere slične strukture, te zaključuje da se u uslovima lažnih početaka i prekida, kao što je slučaj u primeru (2), sastavne klauze smatraju za odvojene CP, pa je time pozicija FNS-a ponovo određena kao inicijalna (Bailey 2011: 26).

Takođe, moglo bi se pretpostaviti da u drugom primeru nije došlo do izostavljanja subjekta, već da je u pitanju relativna klauza sa nultim markerom.

Kao što je i očekivano, najveći broj FNS-a označen je za prvo lice jednine (40\%), praćen drugim licem jednine (15\%).

(4)Vincent: You given a lot of them?

Jules: - Yeah, Ø Got my technique.

Prema rečima Vratilove, kapaciteti različitih pronominalnih oblika da budu izostavljeni iz površinske strukture rečenice, nije isti za sve (Wratil, 2011: 119). Naime, tematski kapacitet se odnosi na istaknutost određenog elementa u konverzaciji, te će u govornom jeziku, najviši nivo istaknutosti imati zamenice prvog lica, a odmah zatim zamenice drugog lice, s obzirom da se najčešće odnose na sagovornike koji direktno sudeluju u govornom činu, te je njihov referent lako nadoknadiv iz situacionog konteksta.

Za razliku od dijaloga filma Pre svitanja, dijalog Petparačkih priča, obiluje primerima FNS-a, te se možemo zapitati na koji način ovo svojstvo govornog jezika doprinosi percepciji dijaloga kao prirodnog. Kao prvo, jedna od osnovnih karakteristika filma Petparačke priče jeste dinamičnost i brzo smenjivanje dijaloških celina, te u tom smislu, FNS jeste efikasno sredstvo kojim se takva dinamičnost i gotovo logoreični govorni stil na granici improvizacije postižu. Analizirajući dijalog Prijatelja, Kvaljo navodi da bi ponavljanje dovelo do usporavanja komunikativnog procesa (Quaglio 2009: 6), koje je u suprotnosti sa dijaloškim načelima Tarantinovog filma.

Zanimljivu pretpostavku o komunikativnoj funkciji izostavljanja subjekta, iznosi i Langaker (Langacker 1985: 138), koji navodi da ovo svojstvo govornog jezika za rezultat ima stvaranje veće intimnosti sa sagovornikom, odnosno gledaocem. Pa ako uzmemo u obzir da osnovu Tarantinovih filmova čine likovi, vrlo često bazirani na portretima ljudi sa margina, 
koji su ušli u istoriju filma kao jedne od najinovativnijih i najomiljenijih fiktivnih kreacija, možemo zaključiti da svojstva govornog jezika, imaju ulogu ne samo da jezik učine prirodnim, već i da funkcionišu kao motor razvijanja celokupnog narativa i njegovih likova.

U dijalogu filma Soba nije pronađen ni jedan primer FNS-a. Pa ipak, ono što je upečatljivo jeste činjenica da je struktura ovog dijaloga zasnovana na prostim S-P-O rečenicama, u kojoj nasuprot izostavljanja subjekta, dolazi do njegovog ponavljanja. Uzmimo u obzir sledeće primere u kojima su kontrastirane dve slične replike iz filmova Soba i Petparačke priče, respektivno.

(5) Mother: He's a wonderful person. He's getting promotion soon. Hebought you a car and he bought you a ring.

(6) Vincent: Then, what'd Marsellus do?

Jules: -Ø Sent a couple of cats over to his place. They took him out on his patio.

$\varnothing$ Threw his ass over the balcony, $\varnothing$ fell four stories.

U primeru (5) mogli bismo da pretpostavimo da se Vajso namerno odlučio za ponavljanje subjekta, zarad postizanja efekta naglašavanja aktera pojedinačnih radnji. $\mathrm{Pa}$ ipak, analizom scenarija, na sličan model nailazimo više puta:

(7) Lisa: I need you, I love you. I don't want to get married anymore.

I don't love Johnny. I dream about you. I need you to make love to me.

Očigledno je da u navedenim primerima, ponavljanje subjekta u ovakvoj meri nije potrebno, te da njegova repetitivna primena u tom slučaju, gubi dramaturški efekat $i$ postaje redundantna.

Stoga, može se zaključiti da u dijalogu filma Soba, odsustvo FNS-a, kao svojstva govornog jezika, zaista utiče na prirodnost dijaloga, odnosno na percepciju scenarija od strane publike kao izveštačenog i repetitivnog. O tome da i lingvistička strana scenarija može biti glavna meta kritike, svedoči i komentar autora Bi-Bi-Sijeve kulturne rubrike Nikolasa Barbera, koji primećuje da se film Soba sastoji od „Devedeset devet minuta Lisinog neprestanog ponavljanja da ne želi da se uda za Džonija (Barber, 2016).”

\section{Pripovedački istorijski prezent}

Analizirajući distribuciju pripovedačkog istorijskog prezenta (u daljem tekstu PIP), u korpusu govornog engleskog jezika američkog varijeteta, Nesa Vulfson navodi dve pretpostavke (Wolfson 1989: 138):

a. Prosto prošlo vreme uvek može biti supstituisano PIP-om, bez promene referencijalnog značenja

b. Narativ nikada nije u potpunosti u sadašnjem vremenu, već prosto prošlo vreme i PIP alteriraju 
Struktura i funkcija PIP-a u korpusu filmskih dijaloga, analizirana je na osnovu ovih pretpostavki.

Osnovna narativna struktura filma Pre svitanja, zasnovana na prikazu jednog dana u životu dvoje ljudi - Selin i Džesija, prati tok njihovog upoznavanja, kroz neprekidne razgovore, bez značajnih sporednih radnji. Instance PIP-a analizirane su u monolozima koji se odnose na prepričavanje prošlih događaja, a ono što je vrlo upečatljivo jeste da je u svakom od monologa upotrebljen PIP. Uzmimo u obzir sledeći primer:

(8) Jesse: ....and through the mist,

I could see my grandmother.

And she was just standing there, smiling at me.

And I held it there for a long time...

....and I looked at her.

And then finally, I let go

of the nozzle, you know?

And then I dropped the hose...

....and she disappeared.

And so I run back inside

and tell my parents.

And they sit me down

and give me this big rap on how...

...when people die, you never see

them again.

U ovoj sceni, Džesi prepričava svoje najupečatljivije iskustvo smrti, u kome PIP-a vrši funkciju oživljavanje prošlosti kroz vrlo slikovit sadašnji narativ. U ovom primeru, ispunjena je pretpostavka da će se PIP javiti u alternaciji sa prošlim vremenom. Međutim, alternacija ima veću ulogu od one koju predlaže Vulfson, a koja se odnosi na to da ne postoji razlika u emotivnom intenzitetu događaja koji su ispričani u PIP-u i prošlom vremenu, te da alternacija jednostavno ima ulogu organizacije diskursa (Wolfson 1989: 143). Pa ipak, ova scena svedoči suprotno; u prvom delu Džesi priča u prošlom vremenu o trenutku kada je potonuvši u omamljenost video prikazu svoje pokojne bake. Nakon toga, dešava se dramaturška promena ritma, praćena promenom glagolskog vremena - trgnuvši se, Džesi se vraća u realnosti i hitajući dolazi do svojih roditelja gde se suočava sa saznanjem da je njegova baka zaista umrla. Pored činjenice da PIP u ovom slučaju zaista ima funkciju u hronološkom razdvajanja narativnih celina, on poput montažnih rezova, muzičke podloge ili kolor korekcija predstavlja i vrlo efektno rediteljsko-dramaturško sredstvo promene raspoloženja na filmskom mikroplanu.

U korpusu filma Petparačke priče broj primera koji sadrže PIP je manji u odnosu na prethodni film, što je takođe srazmerno manjem broju prepričanih prošlih događaja. Od pet primera PIP je korišćen u tri.

U primeru (9), interesantno je primetiti da predikcije Nese Vulfson o alternaciji PIP-a i prošlog vremena nisu ispunjene: 
(9) Young man: Heard about this one bloke, he walks into a bank with a portable phone.

He gives the phone to a teller.

The bloke on the other end says,

"We got this guy's little girl.

If you don't give him all your money,we're gonna kill her."

Razlog za ovo možemo naći u stilskoj markiranosti govornog čina, koji karakteriše upotreba žargona, imitacija glasova, i vrlo žustar i dramatičan ton govornika, koji se gotovo graniče sa strip junacima. U tom smislu, ova diskursna celina markirana je odrednicama ovde i sada, događaj je ispričan vrlo realistično, te možemo reći da se bez oslanjanja na režiserske metode poput flešbeka, postiže efekat odigravanja događaja pred očima sagovornika. U takvoj celini nema mesta vremenskoj distanci koju upotreba prošlog vremena neminovno stvara, a PIP kao i u prethodnom slučaju postaje dramaturški stilizovano svojstvo prirodnog govora, ali i režisersko sredstvo efektnog oživljavanja prošlosti.

U korpusu filma Soba, prisutan je samo jedan primer prepričavanja prošlog događaja.

(10) Peter: Yeah, you've got to establish these guidelines

before you get married.

Speaking of, how'd you ever meet Lisa?

You never told us.

Johnny: Well that's a very interesting story,

when I moved to San Francisco with two suitcases

and I didn't know anyone and I have, uh,

I headed to YMCA with a \$2000 check

which I could not cash.

Well because it was an out of state bank.

Anyway, uh, I was working as a busboy in a hotel, and uh, uh, she was sitting, drinking her coffee, and she was so beautiful, and I say hi to her.

That's how we met.

Slušajući monolog ove scene, čini se da PIP uopšte neće biti upotrebljen, s obzirom da su svi prošli događaji ispričani u prošlom vremenu, sve do poslednje rečenice u kojoj se scenarista iznenada odlučio za sadašnje vreme. Ova struktura je krajnje nezgrapna, s obzirom na to da se PIP ne javlja u alternaciji sa prošlim vremenom, ali ni izolovan kao u prethodnom slučaju. Takođe, PIP u ovom slučaju nema funkciju organizacije diskursa, s obzirom da poslednja rečenica u kojoj je iskoršćen, nikako nije intonativno niti kontekstualno odvojena, već je iskazana u okviru sastavne celine, te ništa ne ukazuje na njenu važnost u diskursu. Vulfson u slučaju ovakvih konstrukcija naglašava da mora postojati vremenska koordinacija između glagola, te ako je prvi glagol u prošlom vremenu, nije moguće da drugi bude u sadašnjem (Wolfson 1989: 147). Sa dramaturške strane, ovakva promena glagolskog vremena bi mogla da indicira promenu iz indirektnog 
u direktan govor koji će uslediti, što u većini slučajeva istovremeno najavljuje vrhunac narativa. Pa ipak, monolog se ovde naglo završava, a celokupna scena zvuči nedovršeno.

Stoga, jasno je da je dijalog filma Soba napisan vrlo nevešto, pa ne samo da zvuči neprirodno jer upotreba PIP-a nije standardna govornom jeziku, već možemo videti kako jedno svojstvo spontanog govora može imati uticaj i na tok narativa, te stvoriti antiklimaks tamo gde on nije predviđen.

\section{Zaključak}

Ova studija pokazala je da svojstva govornog jezika zaista imaju uticaj na percipirani kvalitet filmskog dijaloga. Stav da se filmski dijalog ne može izjednačiti sa svakodnevnom konverzacijom, trebalo bi preformulisati, s obzirom da se takvo mišljenje pre svega odnosi na disfluentnosti, za koje nema mesta u filmskom dijalogu, a koje su posledica ograničenja radne memorije i činjenice da je svakodnevni govor spontan. FNS i PIP prisutni su u korpusu dijaloga prva dva analizirana filma, što je doprinelo ne samo prirodnosti jezika već i poslužilo kao uspešno dramaturško sredstvo u kreiranju likova i dinamičnosti celokupnog narativa. S druge strane, u filmu Soba ovo nije bio slučaj, što je u korelaciji sa opštim sudom da je za loš prijem ovog filma odgovoran upravo dijalog koji nema ništa zajedničko sa svakodnevnim jezikom, te zvuči izveštačeno. Pa ipak, i film kao i spontani govor pripadaju situaciono zavisnom diskursu, te je distribucija svojstava govornog jezika u filmu žanrovski određena, odnosno zavisna od tipa filmskog narativa.

U okviru daljih istraživanja, svakako bi trebalo uključiti filmove različitih žanrova i filmskih škola. Mumblecore žanr, zasnovan na improvizovanom dijalogu, jeste zanimljiva studija slučaja u kojoj bi se moglo utvrditi da li je potpuna prirodnost jezika u korelaciji sa pozitivnom kritikom publike. Kvaljo predlaže sličan eksperiment u kome bismo u filmu uklonili audio-vizuelne parametre kao što su tempo, govorna afektacija, mimika i gestovi (obično u prvom planu kada se analizira filmski dijalog), te ostavili sam tekst sa svojom sintaksičkom strukturom (Quaglio 2009: 2). Tada se postavilja pitanje da li bi i dalje bilo moguće uspešno odrediti ritam dijaloga i u potpunosti spoznati dramaturgiju filma i likova.

Jedna od mogućih primena ovakvog pristupa jeziku filma leži u činjenici da lingvističko-dramaturški interfejs još uvek nije u potpunosti istražen. Upoznavanje sa intuitivnim modelima u odnosu na koje dramaturzi formiraju dijaloge između svojih likova, bio bi dragocen podatak za lingviste koji se bave sintaksom govorog jezika, ali takođe i funkcijama jezika u virtuelnim sredinama. ${ }^{5} \mathrm{~S}$ druge strane, upoznavanje pisaca sa pravilima i obrascima govornog jezika je, prema rečima scenariste Alena Gurnija, izuzetno važno, jer svaki autor prvenstveno treba da spozna kako jezik funkcioniše, da bi znao zašto određeni dijalozi zvuče neprirodno i amaterski, a drugi vrlo prirodno i spontano (Gourney, 2013). Takođe, predočavanje korpusa govornog jezika, predstavljao bi značajan imput za scenariste, s obzirom da filmski dijalog život započinje na papiru. Izloženi jeziku svakodnevnih konverzacija, autori bi, bar kada je u pitanju jezička struktura, bili bliži ostvarenju popularnog dijaloškog ideala - napisan kao da je izgovoren.

5 Videti Juker (2016). 


\section{Literatura}

Bailey, L. (2011). "Null Subjects in Northeastern English" Newcastle Working Papers in Linguistics 17, 23-45. URL: https://kar.kent.ac.uk/42736/1/Nullsubjectsinnorthenenglish.pdf

Biber, D. (1988). Variation Across Speech and Writing. Cambridge: Cambridge University Press.

Baumgarten, N. (2003). "Shaken and stirred: language in flm in a cross-cultural perspective." Zeitschrift für interkulturellen fremdsprachenunterricht 8/2-3, 1-9. URL: http://tujournals.ulb.tudarmstadt.de/index.php/zif/article/viewFile/530/506

Chapman, H. (2017). "Nine rules for writing a dialogue." Novel Writing Help (online). https://www.novel-writing-help.com/writing-dialogue.html (Pristupljeno 30.10.2017).

Forchini, P. (2011). Movie Lnaguage Revisited: Results from Multi-Dimensional Analysis and Corpora. Bern: Peter Lang AG.

Gourney, A. (2013). "The Pattern's the thing: The Use of Grammar in Screenwriting." Five Writers. https://5writers.com/2013/03/01/the-patterns-the-thing-the-uses-of-grammar-inscreenwriting-by-allen-gorney/ (Pristupljeno 1.11.2017)

Hegeman, Lillian and Tabea Ihsane. (2011). "Adult null subjects in the non-pro-drop languages: Two diary dialects." Language Acquisition 9, 329-346.

Kozloff, S. (2000).Overhearing film dialogue. Berkley: University of California Press.

Leech, G. (2000). “ Grammars of Spoken English: New Outcomes of Corpus Oriented Research.” Language Learning 50, 675-724.

Quaglio, Paulo.(2009). Television Dialogue: The Sitcom Friends vs. Natural Conversation. Amsterdam: John Benjamins.

Wolfson, N. 1989. "The conversational historic present.” Linx 20, 135-151. 30.10.2017)

URL: http://www.persee.fr/doc/linx_0246-8743_1989_num_20_1_1125 (Pristupljeno

\section{Tijana Marković}

\section{HOW NATURAL IS THE FILM DIALOGUE? ANALYSIS OF NULL SUBJECT AND CONVERSATIONAL HISTORIC PRESENT IN THE CORPUS OF THREE FILM DIALOGUES}

Summary: The aim of this work is to determine to which degree features of spoken language have an impact on the perceived quality of a film dialogue. The aesthetic notions of 'good' and 'bad' dialogue are susceptible to different audience opinions, but one trait that is almost always mentioned in the context of a good dialogue is the naturalness of its script. Dialogues of the films Before Sunrise and Pulp Fiction have been held in high regard among film critics and audiences since they came out, while the dialogue of the film Room is often considered to be the worst dialogue in the film history. Therefore, this study will analyze two features of spoken language, namely null subjects and conversational historical present, in the corpus of three American films, in order to determine whether the degree of their use is in correlation with the perceived dialogue quality.

Key words: film dialogue, naturalness, screenwriting, spoken language, null subject, historical present 